\title{
Anterior Segment Vascular Casting
}

\author{
J. M. OLVER and A. C. E. McCARTNEY \\ London
}

\begin{abstract}
Summary
Vascular corrosion casting provides a permanent three-dimensional record of the deeper vasculature of the anterior segment whereas fluorescein angiography allows clinical examination of superficial vessels.

Morphological findings on scanning electron microscopy of vascular casts of the anterior segment in sheep are presented and compared with that of man by casting techniques. Sheep illustrate the basic mammalian anterior segment vascular architecture but lack anterior ciliary arteries which connect with the deeper collateral arterial circles.

The casting technique is described and its use to answer comparative anatomical, pathological and clinical questions explained. These techniques are being applied to examine changes to the anterior ciliary arteries and the deeper vessels following strabismus surgery in an animal model.

Scanning electron microscopy of vascular corrosion casts has given a new dimension to micro-vascular anatomy.
\end{abstract}

With the advancement of scanning electron microscopy anatomical casting techniques have entered a new dimension. The original anatomical castings were done by Leonardo da Vinci ${ }^{1}$ in the early sixteenth century using wax to fill the cerebral ventricles. In the mid twentieth century latex was used to fill vessels which were viewed macroscopically following maceration of the surrounding tissue. Using this technique, Ashton, ${ }^{2}$ Wybar $^{3}$ and Hayreh $^{4}$ examined the microcirculation of the posterior segment of the eye and of the orbit. Ashton ${ }^{5}$ also studied the relationship of Schlemn's canal to the anterior segment vasculature. Recently, latex studies have been superceded by low viscosity methyl methacrylate resins ${ }^{6,7}$ used in conjunction with scanning electron microscopy (SEM). SEM improves on light microscopy by allowing greater magnification and depth of focus, with which to examine the microvascular cast three dimensionally. The material now used, methyl methacrylate, has a low viscosity which fills capillaries and withstands electron bombardment during SEM.

The normal ocular microcirculation in $\operatorname{man}^{8.9,10}$ and primates ${ }^{11,12.13}$ (whose anterior segment vasculature appears similar to man) have been studied using SEM. There have been only a few applications of vascular casting techniques to examine pathological ocular or post-surgical repair circulations. These include vascular casts of corneal neovascularisation, ${ }^{14}$ experimental subretinal neovascularisation ${ }^{15,16}$ and non-ocular arterial anastomoses. ${ }^{17}$

Using this technique we have studied the normal microvascular architecture of the anterior segment in sheep to determine if this

This paper was presented as a poster at the annual meeting of the Ophthalmology Society of the United Kingdom in April 1988.

Correspondence to: Jane M. Olver FRCS, Institute of Ophthalmology. 17-25 Cayton Street, London EC1V 9AT. 
model can be used to help identify the morphological changes following squint surgery.

\section{Casting methods}

Adult Clun sheep were anaesthetised and heparinised. The ocular vessels were flushed free of blood by primary perfusion through the carotid arteries with phosphate buffered saline at physiological temperature. Freshly prepared resin (secondary perfusate) was injected at a pressure of $90-120 \mathrm{~mm} \mu \mathrm{g}$ into each carotid artery until it appeared through the opened jugular veins. The resin was prepared using a modification of Nopanitaya's method. ${ }^{18} \mathrm{Com}$ mercially available Batson's No. 17, (Polysciences Ltd)* was used. This contains base resin pre-polymerised methacrylate, separate catalyst (peroxide) and accelerator (n-Ndimethylalinine). The resin was thinned by the addition of monomeric methyl methacrylate (de Trey and Alldrich). The proportions used for each aliquot prepared are: base methacrylate $25 \mathrm{ml}$, catalyst $7.5 \mathrm{ml}$, promoter $0.7 \mathrm{ml}$, mono methyl methacrylate $12.5-15 \mathrm{ml}$. Although coloured pigments may be added to the clear resin, these were not used.

The material was left one hour in water at $50^{\circ} \mathrm{C}$ for the resin to polymerise. The orbits were excised and the tissue surrounding the cast was macerated in $6 \mathrm{M}$ potassium hydroxide. The resultant casts were washed thoroughly in tap water followed by distilled water then air dried. The injection replicas of the vascular lumen (corrosion casts) were sputter coated with a $50 \mathrm{~nm}$ coating of gold and examined using scanning electron microscopy.

The vascular casts of the eye, especially the anterior segment were extremely fragile, but could be examined at magnifications of up to $\times 6,000$ at an accelerating voltage of $20 \mathrm{kV}$ for short periods of time. Working magnifications were usually of the order of $\times 100$ to $\times 3,000$ at an accelerating voltage of $20 \mathrm{kV}$. Vessels were traced three-dimensionally and the cast microdissected to reveal the underlying vascular structure.

\section{Findings}

Orientation of the overall vascular structure of the anterior segment is shown viewed mac- roscopically in Figure 1 but full morphological interpretation is limited by the low resolution. The long posterior ciliary arteries are evident in Figure 1a, coursing towards the iris where they divided to form a virtually complete coronally placed arterial circle. Part of the complete arterial circle is shown in Figure $1 \mathrm{~b}$ where it can be seen that no large vessels pass over it, and from which a second inner incomplete arterial circle is formed, off which the iris arterioles arise which are just visible (small arrow). Detail of the posterior aspect of the anterior segment showing the vessels of the ciliary processes are shown in Figure 1c.

The depth of field and three dimensional viewing possible with SEM allowed full morphological interpretation. Arteries were distinguishable from veins by the characteristic appearance of the endothelial nuclear impressions; arteries and arterioles have elongated oval impressions, (see Figure 2) whilst veins and venules have typical more rounded impressions, (see Figure 3). The low viscosity of the resin allowed capillaries to be filled and identified by their size and lack of nuclear "impressions" (see Figure 4).

From the anterior view of the anterior segment vasculature in Figure 5, part of the complete arterial circle is seen (solid arrow), off which arises an incomplete arterial circle (hollow arrow). The incomplete arterial circle in turn gives rise to spiral iris arterioles (solid star) and posterior recurrent arteries to the anterior choroid (hollow star). Neither the complete or incomplete arterial circles are joined by anterior ciliary arteries.

The anterior aspect of the ciliary processes (small white arrows) are shown in Figure 6 with the iris vessels in the foreground. The iris arterioles, barely visible in Figure $1 b$, are clearly defined in Figure 7 by their characteristic spiral shape.

\section{Discussion}

The deeper collateral circulation of the anterior segment in mammals consists of a virtually complete arterial circle supplied by the long posterior ciliary arteries, which gives rise to an incomplete arterial circle from which the iris arterioles originate. 

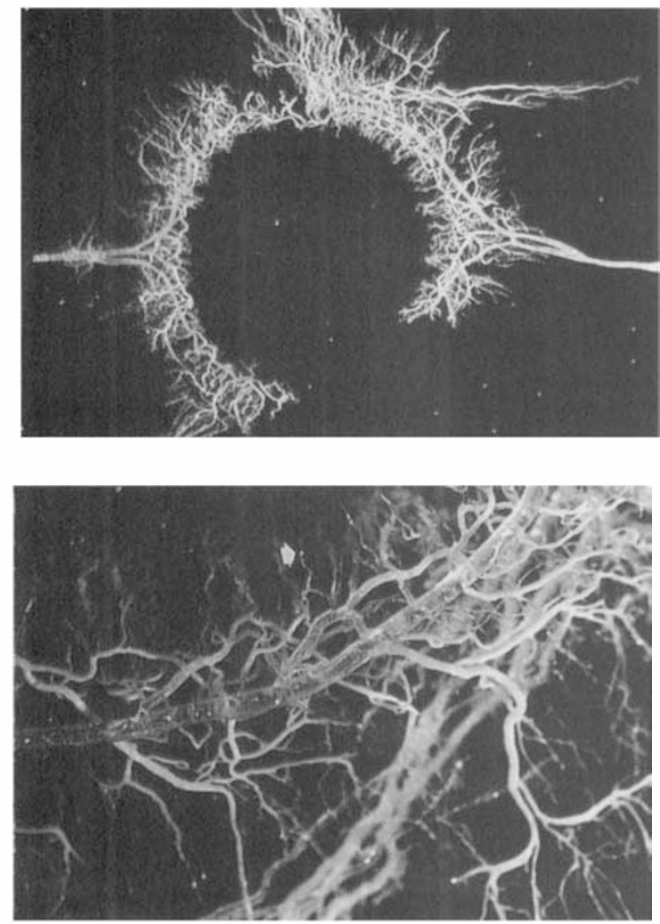

This study shows that in sheep the complete and incomplete arterial circles lie on the iris. In $\operatorname{man}^{8}$ and subhuman primates ${ }^{13}$ the complete arterial circle lies within the ciliary body (intramuscular arterial circle) and the incomplete arterial circle (major arterial circle of the iris) lies at the iris root where it is sometimes visible in the peripheral iris. In sheep there are only a few anterior ciliary arteries which remain superficially located and do not connect with the deep arterial circles. In pigs ${ }^{19}$ the anterior ciliary arteries have a diverse origin from the superior and inferior rectus muscular arteries, off the retractor bulbi muscles and from the long and short posterior ciliary arteries. These penetrate the sclera but do not connect directly with the arterial circles above.

In contrast, $\operatorname{man}^{8}$ and subhuman primates ${ }^{13}$ have anterior ciliary arteries predominantly of muscular artery origin which connect directly with the intramuscular arterial circle either through direct perforators or through perforating branches from the anterior episcleral arterial circle.

Anterior segment ischaemia is a rare but serious complication of strabismus surgery on

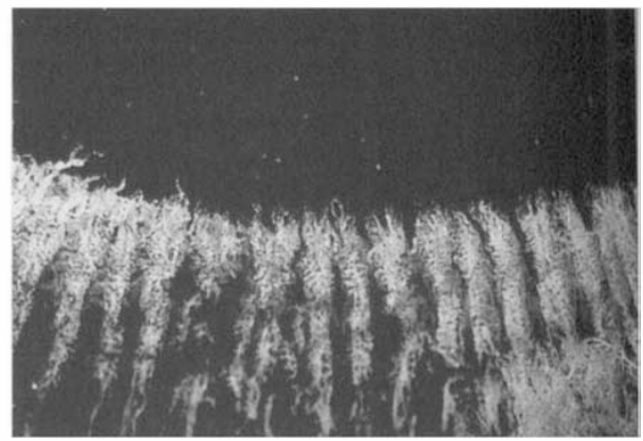

Fig. 1. Macroscopic casts (1a) Low magnification photomicrograph of long posterior ciliary arteries and complete arterial circle of the iris. (sheep) (1b) High magnification photomicrograph of part of complete arterial circle of the iris. Note absence of connecting anterior ciliary arteries. (sheep) (1c) High magnification photomicrograph of posterior aspect of ciliary processes. (sheep)

two or more rectus muscles in adults ${ }^{20-24}$ and has only rarely been described in childre ${ }^{24.25}$ in which there were other significant ocular abnormalities. It is accepted surgical practice to limit such operations to movement of two muscles at any one time and postpone further surgery for 2-3 months. Although experimental studies can reproduce anterior segment ischaemia ${ }^{26-31}$ the changes in vascular architecture which result in restored blood flow to the iris have not been determined. Saunders and Sandell ${ }^{21}$ suggested, from anecdotal evidence, that there was no blood flow through the ciliary arteries in previously tenotomised rectus muscles. In an opposing view, Simon et al. ${ }^{23}$ suggested that re-establishment of the original anterior ciliary circulation might occur following strabismus surgery and France in the discussion following Simon's paper gave anecdotal evidence that the anterior ciliary arteries recanalised.

Alterations in vascular dynamics have been demonstrated following strabismus surgery by anterior segment fluorescein angiography. ${ }^{31}$ Characteristic iris segmental filling defects have been demonstrated in adults following 


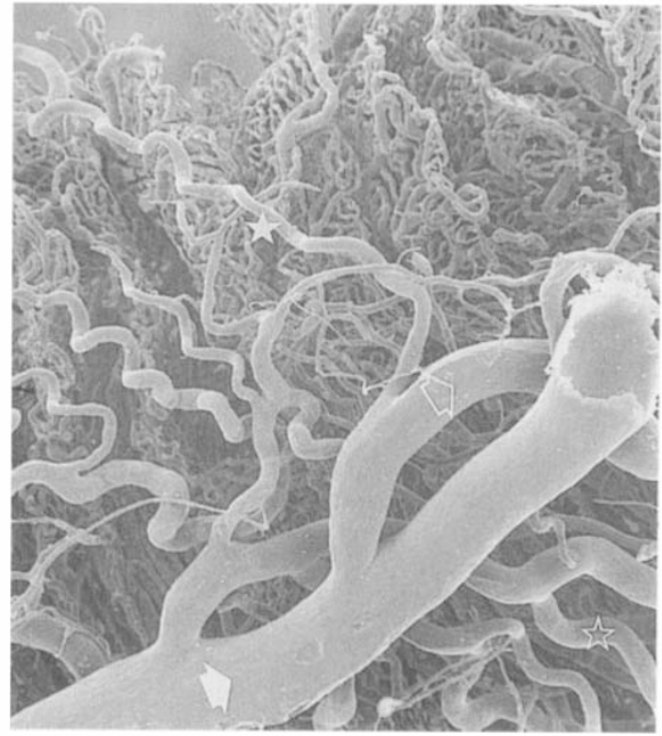

Fig. 2. Scanning electron micrograph of part of complete arterial circle of the iris (equivalent to the intramuscular arterial circle in man) (white arrow). In sheep this lies well within the iris. Spiral iris arterioles (*) and posterior recurrent arteries to the anterior choroid $\left(\right.$ empty $\left.{ }^{*}\right)$ are seen arising from the incomplete arterial circle (equivalent to major arterial circle of the iris in man) (empty arrow), anterior to the complete arterial circle. $($ sheep $\times 100)$.

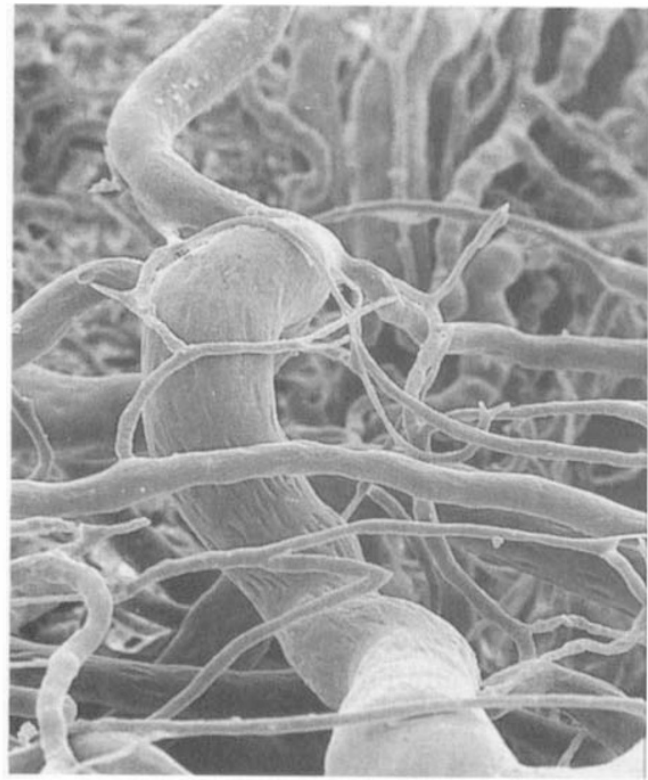

Fig. 3. Scanning electron micrograph showing mass of fine capillaries traversing iris arteriole. (sheep $\times 320)$

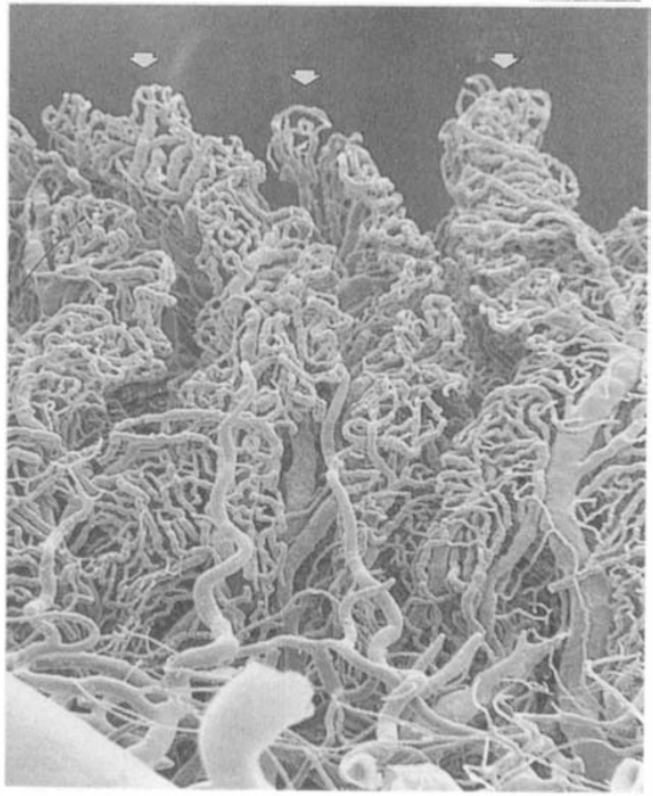

Fig. 4. Scanning electron micrograph showing anterior aspect of ciliary processes (arrows) with fine iris capillaries and iris arteriole in the lower field. (sheep $\times 100$ )

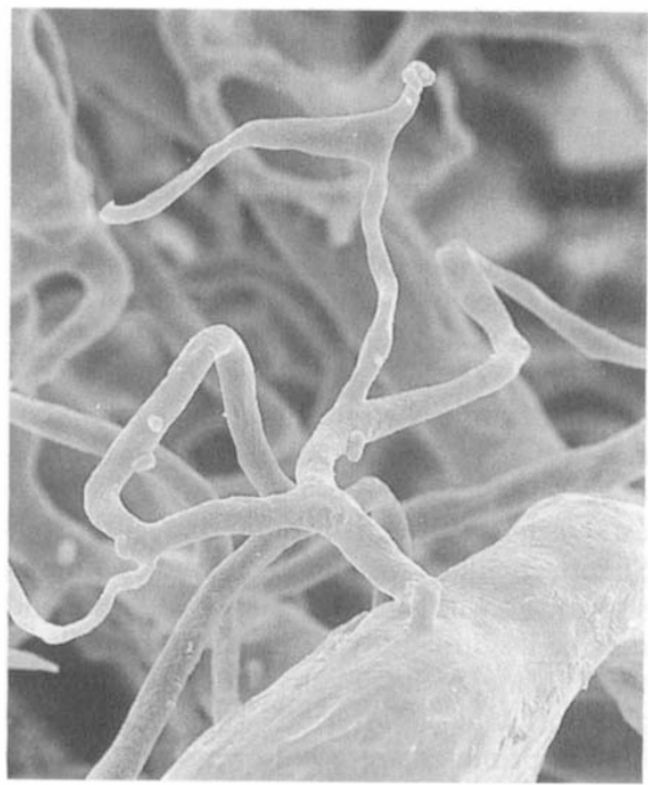

Fig. 5. Scanning electron micrograph showing fine capillaries branching from arteriole. $($ sheep $\times 844)$ 


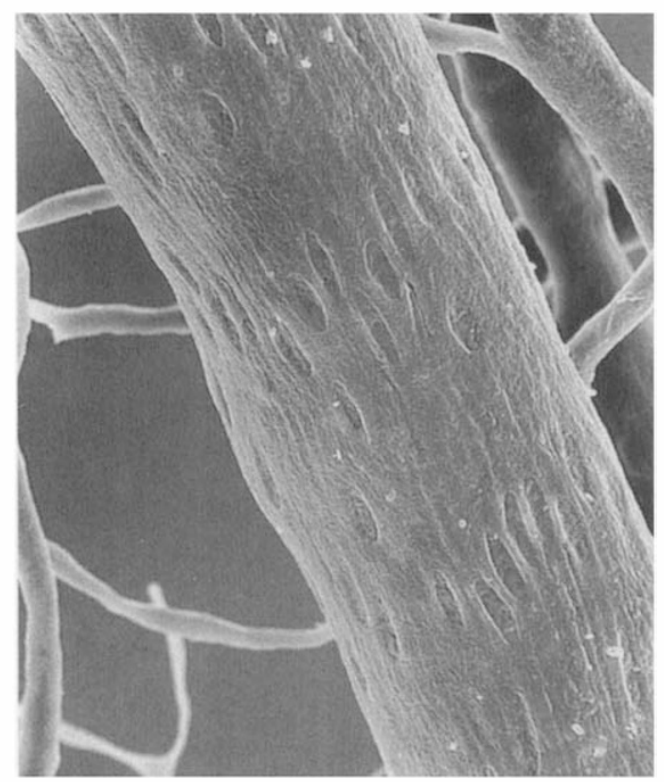

Fig. 6. Scanning electron micrograph of posterior recurrent artery to the anterior choroid showing characteristic nuclear impressions. $($ sheep $\times 844)$

vertical rectus muscle surgery. ${ }^{32}$ Recent work (Olver) has shown that primary vertical rectus muscle surgery results in sector filling delay but that secondary vertical rectus muscle surgery does not. Low dose fluorescein episcleral angiography which allows a clear interpretation of the episcleral vessels ${ }^{33}$ has shown that there is no re-establishment of blood flow through the tenotomised rectus muscle (Olver, unpublished data).

These angiographic findings strongly suggest that recanalisation of the anterior ciliary arteries does not occur.

Vascular casting can be used to observe the effects of surgery on the anterior segment circulation in an animal model and provide evidence of whether or not a new circulation is established through the muscle insertion. Sheep ocular vasculature shows many similarities with human ocular vasculature and may be used to study basic vascular architecture. Sheep, however, lack penetrating anterior ciliary arteries, suggesting nonhuman primates are a better model to study changes in anterior segment vasculature following strabismus surgery. This future application is underway and will be reported upon.

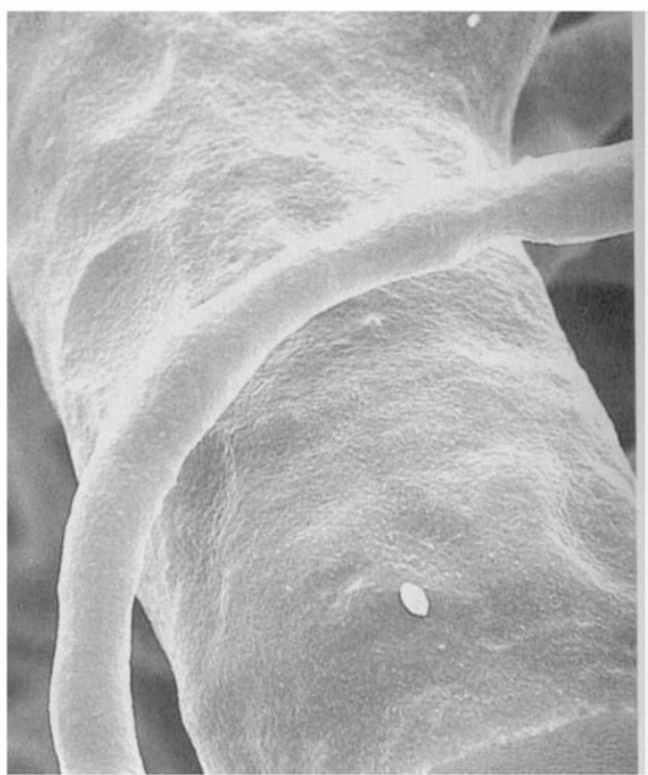

Fig. 7. Scanning electron micrograph of ciliary process vein with overlying venule showing characteristic endothelial nuclear impressions. (sheep $\times 2,080)$

In summary, vascular casting extends our knowledge of anterior segment circulation gained from fluorescein angiography by demonstrating the normal presence or absence of anterior ciliary arteries connecting with deeper arterial circles, clarifying the existence of two deeper arterial circles, one complete and one incomplete and the origin of the iris arterioles. Casting may both identify the normal ocular microcirculation and be applied to examine pathological ocular microcirculation, in particular the nature and morphology of new vessels thus helping to answer both basic scientific and clinical questions. The limitation of this technique is that functional characteristics of vascular flow can only be inferred from the structural findings.

We suggest that casting is a suitable technique with which to study the changes to the anterior segment vasculature following strabismus surgery, particularly the circulation around the altered muscle insertion, the "strabismus scar".

We are grateful to de Trey and Alldrich for their support. Our thanks also to Robin Howes for technical 
assistance. This work is supported by the Francis and Renee Hock Trust.

\section{References}

${ }^{1}$ da Vinci L: c 1508. The brain injected to demonstrate the shape of the cerebral ventricles. Royal Library, Windsor Castle. Cat 19127. R. Anatomical drawings from the Royal Collection. Royal Academy of Arts, London 1977, p 48 and plate 10.

${ }^{2}$ Ashton N: Observations on the choroidal circulation. Br J Ophthalmol 1952, 36: 465-81.

${ }^{3}$ Wybar KC: A study of the choroidal circulation of the eye in man. J Anat 1954, 88: 94-101.

${ }^{4}$ Hayreh SS and Dass R: The ophthalmic artery. Part I. Origin and intra-cranial and intra-canalicular course. Part II. Intra-orbital course. $\mathrm{Br} J$ Ophthalmol 1962, 46: 212-47.

${ }^{5}$ Ashton N: Anatomical study of Schlemm's canal and aqueous veins by means of neoprene casts. Part I. Aqueous veins. Br J Ophthalmol 1951, 35: 291303. Part II. Aqueous veins cont. Br J Ophthalmol 1952, 36: 265-67. Part III. Arterial relations of Schlemm's Canal. Br J Ophthalmol 1953, 37: 57786.

${ }^{6}$ Nowell JA, Pangborn J, Tyler WS: Scanning electron microscopy of the avian lung in Scanning Electron Microscopy. Ed. Johari O, IIT Research Institute Chicago Illinois 1970, 249-56.

${ }^{7}$ Murakami T: Application of the scanning electron microscope to the study of the fine distribution of the blood vessels. Arch Histol Jap 1971, 32: 44554.

${ }^{8}$ Woodlief NF: Initial observations on the Ocular Microcirculation in Man. Arch Ophthalmol 1980, 98: $1268-72$.

${ }^{9}$ Fryczkowski AW, Grimson BS, Peiffer RL: Vascular casting and scanning electron microscopy of human ocular vascular abnormalities. Arch Ophthalmol 1985, 103: 118-20.

10 Yoneya S, Tso MOM: Angioarchitecture of the human choroid. Arch Ophthalmol 1987, 195: 681-7.

${ }^{11}$ Shimizu K and Ujiie K: Structure of Ocular Vessels. Igaku-Shoin Medical Publishers, New York, 1978.

12 Morrison JC and Van Buskirk M: Anterior collateral circulation in the primate eye. Ophthalmology 1983, 90: 707-15.

${ }^{13}$ Morrison JC, DeFrank MP, Van Buskirk EM: Comparative Microvascular Anatomy of Mammalian Ciliary Processes. Ophthalmology 1987, 28: 132540.

${ }^{14}$ Burger PC, Chandler DB, Klintworth GK: Corneal neovascularisation as studied by scanning electron microscopy of vascular casts. Lab Invest 1983, 48: 169-80.

15 Ohkuma H and Ryan SJ: Vascular casts of experimental subretinal neovascularisation in monkeys. Invest Ophthalmol 1983, 24: 481-90.

${ }^{16}$ Tano Y, Chandler DB, Machemer R. Vascular casts of experimental retinal neovascularisation. Am J Ophthalmol 1981; 92: 110-20.

17 van Gelder PA and Klopper PJ: Healing of micro- vascular arterial anastomoses as seen on corrosion casts by scanning electron microscopy. Plas Reconstruc Surg 1979, 64: 59-64.

${ }_{18}$ Nopanitaya W, Aghajanian JG, Gray LD: An improved plastic mixture for corrosion casting of the gastro-intestinal microvascular system. SEM 1979: Part III, SEM, Inc AMF O'Hare., I1 60666, 751-755.

${ }^{19}$ Simoen P. In Simoens P (thesis): Morphologic study of the vasculature in the orbit and eyeball of the pig. 1985. State University of Ghent, pp 217.

${ }^{20}$ Fells $\mathrm{P}$ and Marsh RJ: Anterior segment ischaemia following surgery on two rectus muscles. In Reinecke RD (Ed): Strabismus. Proceedigns of the Third Meeting of the International Strabismological Association, May 10-12, 1978, Kyoto, Japan. New York, Grune \& Stratton, Inc, 1978, 375-80.

${ }^{21}$ Saunders RA and Sandall GS: Anterior segment ischaemia syndrome following rectus muscle transposition. Am J Ophthalmol 1982, 93: 34-48.

22 Jacobs DS, Vastine DW, Urist MJ: Anterior segment ischaemia and sector iris atrophy. After strabismus surgery in a patient with chronic lymphocytic leukaemia. Ophthalmic Surg 1976, 7: 42-8.

${ }^{23}$ Simon JW, Price EC, Krohel GB, Poulin RW, Reinecke RD: Anterior segment ischaemia following strabismus surgery. J Paed Ophthalmol \& Strab 1984, 21: 179-84. (Discussion by France TD p 185).

${ }^{24}$ France TD and Simon JW: Anterior segment ischaemia syndrome following muscle surgery: The AAPO\&S experience. J Paed Ophthalmol \& Strab 1986, 23: 87-91.

${ }^{25}$ Elsas FJ and Witherspoon CD: Anterior segment ischaemia after strabismus surgery in a child. $A m \mathrm{~J}$ Ophthalmol 1987, 103: 833-4.

${ }_{26}$ Anderson DM and Morin JD: Experimental anterior segment necrosis and rubeosis iridis. Can J Ophthalmol 1971, 6: 196-201.

${ }^{27}$ Hiatt RL: Production of anterior segment ischaemia. J Paed Ophthalmol \& Strab 1978, 15: 197-204.

${ }^{28}$ Freeman HM, Hawkins WR, Schepens CL: Anterior segment necrosis. An experimental study. Arch Ophthalmol 1966, 75: 644-50.

${ }^{29}$ Kottow M, Wassilewa P, Hendrickson P: Provoked iris ischaemia in the rabbit: A fluorescein angiographic study. Can J Ophthalmol 1975, 10: 255-62.

${ }^{30}$ Wilcox LM, Keough EM, Connolly RJ: Regional ischaemia and compensatory vascular dynamics following selective tenotomy in primates. Exp Eye Res 1981, 33: 353-60.

31 Virdi PS and Hayreh SS: Anterior segment ischaemia after recession of various recti. An experimental study. Ophthalmology 1987, 94: 10 1258-71.

32 Hayreh SS and Scott WE: Fluorescein Iris Angiography. II. Disturbance in iris circulation following strabismus operations on various recti. Arch Ophthalmol 1978, 96: 1390-400.

${ }^{33}$ Meyer PAR and Watson P: Low dose fluorescein angiography of the conjunctiva and episclera. $\mathrm{Br} \mathrm{J}$ Ophthalmol 1987, 71: 2-10. 